\title{
EL MARGEN DE APRECIACIÓN NACIONAL EN LAS SENTENCIAS DEL TRIBUNAL EUROPEO DE DERECHOS HUMANOS RELATIVAS AL DERECHO A ELECCIONES LIBRES ${ }^{1}$
}

\author{
Pablo Sánchez-Molina
}

«Las Altas Partes Contratantes se comprometen a organizar, a intervalos razonables, elecciones libres con escrutinio secreto, en condiciones que garanticen la libre expresión de la opinión del pueblo en la elección del cuerpo legislativo» Artículo 3 del Protocolo adicional del Convenio Europeo de Derechos Humanos.

\footnotetext{
Sumario: 1. Introducción. 2. El Margen de APRECiación ESTATAL. 3. Alcance del Margen de Apreciación en las Sentencias del Tribunal Europeo de Derechos Humanos relativas al derecho a Elecciones libres. 4. Conclusiones. 5. Bibliografía Citada.
}

\section{INTRODUCCIÓN}

Con la fórmula solemne citada al inicio de este trabajo, el Convenio Europeo de Derechos Humanos (CEDH) recoge el derecho a elecciones libres. Estas constituyen la base para la construcción de un Estado democrático, lo que le dota de una importancia vital al conformar el punto de partida desde el que se desarrollan todos los derechos y obligaciones en las sociedades actua-

${ }^{1}$ El presente trabajo se integra en el Proyecto de investigación de la DGCyT Votex4e «Reforma electoral y derechos de participación de los extranjeros residentes en España: el derecho de sufragio en las elecciones generales, europeas, autonómicas y locales», Referencia DER2012-34411. Agradezco a los miembros del proyecto, en particular a su IP, profesor Ángel Rodríguez (Catedrático de Derecho Constitucional de la Universidad de Málaga), la gran ayuda prestada para su realización. 
les así como su marco de actuación, o lo que es lo mismo, el principal límite de los detentadores del poder para que el elemento «democrático» no quede desnaturalizado.

De la lectura del precepto en cuestión se puede extraer los principales compromisos que adquieren los Estados parte del Convenio, a saber: realizar en periodos razonables unas elecciones libres, con voto secreto (no escrutinio secreto, como equivocadamente establece la traducción española del precepto $^{2}$ ) y que garanticen la libre exteriorización de la voluntad del pueblo.

Dicho precepto, así como la totalidad de los que forman el Convenio, carecería de eficacia jurídica directa sin una instancia encargada de controlar su aplicación. El Tribunal Europeo de Derechos Humanos (TEDH) es el garante de que los derechos allí recogidos sean aplicados de forma efectiva, conformando su jurisprudencia el punto de partida de nuestro objeto de estudio. A pesar de que sus resoluciones tengan el carácter de declarativas gozan de una considerable fuerza debido al alto grado de reconocimiento de dicha institución, siendo además un estadio previo a los Estados interesados en formar parte de la UE, así como por el desprestigio que suponen los pronunciamientos negativos de Estrasburgo.

Como es sabido, el TEDH es el encargado de enjuiciar si algún Estado parte ha vulnerado los derechos reconocidos en el Convenio estableciendo, a tal efecto, un mínimo común denominador de protección. Por lo tanto, la protección derivada de su aplicación hace que los Estados parte tengan la obligación de, al menos, regular los derechos recogidos en el mismo conforme a esa mínima protección, no existiendo ningún inconveniente en que las regulaciones de los mismos protejan dichos derechos con una mayor amplitud.

Sin embargo, al ser la finalidad principal del TEDH establecer una mínima protección que sea efectivamente respetada por sus destinatarios y que, por lo tanto, sus resoluciones no queden en papel mojado, el propio Tribunal reconoce en los supuestos en los que no existe un consenso más o menos amplio entre los mismos un margen de apreciación que permitirá a los Estados, en esa ma-

${ }^{2}$ En este sentido García RocA, «La traducción española del Convenio dicta de ser feliz, pues introduce la expresión «escrutinio secreto» que me parece técnicamente incorrecta. En nuestro Derecho - pero también en la misma lógica intrínseca del proceso electoral- el escrutinio es un momento posterior al de la votación que se realiza antes las Mesas y luego ante las Juntas Electorales. En buena lógica jurídica, el secreto se predica de la forma de expresión del sufragio y sirve a garantizar una libre decisión de cada ciudadano, inmune a coacciones externas, pero no del escrutinio que, por el contrario, debe ser público, ya que la trasparencia del recuento deviene una garantía de la regularidad». En García Roca, J. y Santolaya Machetti, P., La Europa de los derechos, el Convenio Europeo de Derechos Humanos, Centro de Estudios Políticos y Constitucionales, Madrid, 2009, p. 907. 
teria concreta o en determinados ámbitos de la misma, regularlo internamente conforme a lo que el propio Estado considere, sin abandonar los límites infranqueables dentro de las cuales el propio Tribunal concede dicho margen. Además este tiene la posibilidad de ensancharse o estrecharse dependiendo de la interpretación que haga de él el propio Tribunal en el supuesto concreto.

Pues bien, el objeto del presente trabajo es el análisis de los casos en los que el TEDH ha aplicado la doctrina del margen de apreciación al derecho a elecciones libres. Para ello, en primer lugar se conformará el marco teórico dentro del cual se desenvuelve el margen de apreciación; a continuación, nos centraremos en conocer cuál ha sido su aplicación en relación con el derecho a elecciones libres; ello nos permitirá, finalmente, identificar la existencia de pautas específicas en la aplicación de dicho margen de apreciación a este derecho y concretar los límites que Estrasburgo impone a su uso.

\section{EL MARGEN DE APRECIACIÓN ESTATAL}

Como es bien sabido, en el transcurso de las dos guerras que asolaron Europa durante la primera mitad del siglo XX, y como consecuencia de los abusos producidos, tuvieron lugar numerosas violaciones de Derechos $\mathrm{Hu}-$ manos. Tras estos acontecimientos, algunos Estados de Europa Occidental llegaron a la conclusión de que lo sucedido no podía volver a repetirse. Para ello, se plantearon la creación de un espacio común dentro del cual se protegieran una serie de derechos imprescindibles para la convivencia democráti$\mathrm{ca}^{3}$. Bajo este prisma nació en 1950 el Convenio Europeo de Derechos Humanos, en cuya redacción original se incluyeron una serie de derechos comunes a las sociedades democráticas contemporáneas. Entre otros destacan el derecho a la vida, a la libertad deambulatoria, de pensamiento, reunión y expresión, y a un recurso efectivo. Se incorporaron también un conjunto de prohibiciones (contra la esclavitud, la tortura y la discriminación) y el principio de legalidad penal, en virtud del cual no hay pena sin ley. Con el paso del tiempo se fueron incorporando nuevos derechos a través una serie de protocolos. Entre éstos, destacan la protección de la propiedad, el derecho a elecciones libres, a la educación, a un recurso penal, a no ser doblemente condenado por una misma infracción y la abolición de la pena de muerte.

Dichos protocolos no fueron la única vía mediante la que el Convenio ha ido evolucionando, en esta tarea el TEDH ha tenido, y continua teniendo, una

${ }^{3}$ «Considerando que la finalidad del Consejo de Europa es realizar una unión más estrecha entre sus miembros, y que uno de los medios para alcanzar esta finalidad es la protección y el desarrollo de los derechos humanos y de las libertades fundamentales», Convenio Europeo de Derechos Humanos de 4 de noviembre de 1950, hecho en Roma. Instrumento de Ratificación de 26 de septiembre de 1979, Boletín Oficial del Estado, 10 de octubre de 1979, n. $^{\circ} 243$, p. 23564. 
importancia capital. Este es creado a través del artículo 19 del Convenio para asegurar el acatamiento de las obligaciones derivadas del mismo para con los estados signatarios. A raíz de su jurisprudencia se ha ido conformando una interpretación que ha ayudado notablemente en la evolución de los derechos reconocidos. Dicha evolución interpretativa ha configurado una medida para dar solución a la aparente contradicción entre soberanía nacional y el reconocimiento de una serie de Derechos Humanos a nivel europeo. Nace así la doctrina del margen de apreciación nacional. Esta figura conforma el anclaje teórico sobre el que se sustentará toda esta investigación.

La primera ocasión en que el TEDH fundamentó esta doctrina fue en el Caso Handyside ${ }^{4}$. El TEDH consideró que en un ámbito en el que no había una posición uniforme entre los Estados parte, como era la protección de la moral, las autoridades nacionales gozaban de un cierto margen de apreciación al estar en una mejor posición para decidir. Es decir, el TEDH concede a los Estados una cierta deferencia al aplicar las restricciones a derechos fijadas en el Convenio en ámbitos en los que no existe un consenso europeo. Deferencia que no es absoluta, correspondiendo al propio Tribunal la consideración de la idoneidad de su uso a través de un juicio de proporcionalidad. Asimismo, en el Caso Sunday Times se concretó la fundamentación dada al hacerse depender su amplitud del grado de objetividad de los fines perseguidos (a más, menor margen) ${ }^{5}$.

Existen muchas y muy buenas investigaciones nacionales e internacionales sobre la doctrina del «margen de apreciación nacional» ${ }^{6}$. En estas, el

${ }^{4}$ Caso Handyside contra Reino Unido, Sentencia de 7 de diciembre de 1976, en esta ocasión el TEDH consideró que quedaba comprendido dentro del margen de apreciación estatal y que, por lo tanto, era conforme con el artículo 10 del Convenio la prohibición de publicación de The Little Redbook for Students al considerarse que la restricción de la libertad de expresión estaba justificada al ser necesaria en una sociedad democrática para la protección de la moral. Dicha prohibición se sustentó en la consideración de que el manual, destinado a menores, atentaba contra la moral pública al tratar cuestiones acerca de sexo, drogas, etc.

${ }_{5}^{5}$ Caso Sunday Times contra Reino Unido, Sentencia de 26 de abril de 1979, en la que no fue considerada proporcional la prohibición hecha por las autoridades británicas al periódico Sunday Times de publicar cierta información sobre los efectos secundarios producidos por la Talidomida. El Tribunal consideró que la medida no era proporcional al fin perseguido, este es, garantizar la autoridad del poder judicial, estableciendo que la amplitud del margen era menor que en el caso Handyside al corresponder dicha garantía a un fin mucho más objetivo.

${ }^{6}$ Veáse ARAI-TAKAHASHI, Y., The margin of appreciation doctrine and the principle of proportionality in the jurisprudence of the ECHR, Intersentia, Antwerp-Oxford-Nueva York, 2002; DE GouTTES, R., «La théorie de la marge d'appreciation dans la jurisprudence récente de la Cour Européenne des Droits de l'Homme», Revue Trimestrielle des Droits de l'Homme, $\mathrm{n}^{\circ}$ 24, 1995, pp. 566-614; GALETTA, D., «Il principio de proporzionalità nella Convenzione Europea dei Diritti dell'Uomo, fra principio di necessarietà e doctrina del margine di apprezzamento statale: riflessioni generali su contenuti e rilevanza 
margen se define como «the breadth of deference» ${ }^{7}$ o un «espacio de maniobra ${ }^{8}{ }^{8}$ que el TEDH otorga a las autoridades nacionales. Además desde la doctrina española se ha conceptuado como una «regla de no decisión», una «suerte de deferencia europea hacia la decisión interna (...) derivado de la prudencia y la subsidiariedad inherente a la protección internacional» ${ }^{9}$.

Hay que tener en cuenta que la finalidad del CEDH, como ya quedó dicho anteriormente, es la protección de una serie de derechos imprescindibles para la convivencia democrática. Su jurisdicción asegura exclusivamente un mínimo común por lo que cualquier actuación sobreprotectora por parte de los Estados quedará amparada, como no podía ser de otro modo, por el propio CEDH. Todo ello lleva a afirmar que el sistema de protección de Derechos Humanos instaurado por el Convenio impone una homogeneización de un mínimo exigido en los derechos allí reconocidos. Homogeneización que implica integración, dotando al Convenio de la característica de ser un sistema de protección internacional sui generis.

A pesar de ello, en ocasiones, el TEDH puede establecer que no se ha violado el Convenio ante ciertas actuaciones de los Estados parte que renuncia a enjuiciar. Para llegar a este resultado aparentemente contradictorio el Tribunal hace referencia al margen de apreciación nacional. Así, bajo la concurrencia de determinadas circunstancias, el juicio de Estrasburgo declara su conformidad respecto de ciertas actuaciones, regulaciones o fallos de los tribunales de los Estados parte que a priori irían en contra de los derechos allí protegidos.

Se puede justificar el uso de la doctrina del margen de apreciación en base a dos argumentos. Conforme al primero de ellos, el CEDH y sus respectivos

effettiva del principio», Rivista Italiana di Diritto Pubblico Comunitario, $\mathrm{n}^{\circ}$ 3-4, 1999 , pp. 743-771; GARCíA RoCA, J., El margen de apreciación nacional en la interpretación del Convenio Europeo de Derechos Humanos: soberanía e integración, Civitas, Madrid, 2010; Yourow, H., The margin of appreciation doctrine in the dynamics of European Human Rights jurisprudence, Kluwer Law International, La Haya/Boston/Londres, 1996.

${ }^{7}$ Definición de Yourow basándose en la dada por el TEDH en el caso Sunday Times contra el Reino Unido que se analizará a continuación. «It can be defined as the the breadth of deference the Strasbourg organs will allow to national legislative, executive, administrative and judicial bodies before they will disallow a national derogation from the Convention, or before they will find a restriction of a substantive Convention right incompatible with a State Party>s obligations under the Convention.» Yourow, H., «The Margin of Appreciation Doctrine in the dynamics of European Human Rights Jurisprudence», Connecticut Journal of Int'l Law, Vol. 3:111, 1987, p. 118.

${ }^{8}$ GREER, S., The margin of appreciation: interpretation and discretion under the European Convention on Human Rights, Council of Europe Publishing, Strasbourg, 2000, p. 5. También citado en GARCÍA RocA, J., El margen de apreciación nacional en la interpretación del Convenio Europeo de Derechos Humanos: soberanía e integración, Civitas, Madrid, 2010, p. 108.

${ }_{9}$ García Roca, J. (2010), pp. 113-114. 
protocolos son ratificados por los diferentes Estados del mismo modo que el resto de tratados internacionales, conformando este una protección subsidiaria. Aun así, la jurisdicción de Estrasburgo se ha ido constituyendo como un verdadero amparo europeo, como un sistema de protección cuasi constitucional. Su objeto de protección favorece la integración de los Estados parte así como la homogeneización de sus derechos más significativos en las relaciones entre individuos, los Derechos Humanos. En cuanto al segundo, para lograr un verdadero amparo europeo no basta con contar con excelentes argumentaciones de Estrasburgo sino que estas deben ser satisfechas. Para ello, no se debe perderse de vista su consideración de subsidiaria así como la importancia de lograr un consenso alrededor de su campo de actuación. En base a esta finalidad, el Tribunal hace referencia al margen de apreciación, permitiendo que en ciertos derechos en los que no exista un consenso en su aplicación cada Estado tenga la posibilidad de protegerlo conforme a sus cánones internos. Aun así, no toda regulación estaría protegida por el margen sino que esta dependerá de una serie de factores que serán objetos de un análisis posterior en relación con el derecho a elecciones libres.

En definitiva, nos encontramos ante una figura jurisprudencial que actúa como principio general interpretativo de los derechos del Convenio en los que no existe un consenso en su aplicación entre los diferentes Estados parte. Entre ellos, se encuentran países con diversas realidades sociales, económicas, culturales y, por lo tanto, tradiciones jurídicas muy distintas. En este sentido, el margen posibilita el cumplimiento del mínimo de protección exigido por el Convenio sin quebrar el pacto alcanzado en 1950 y demuestra que en ciertas cuestiones controvertidas existen diferentes formas de aplicar el mismo derecho sin que por ello deba considerarse vulnerado. Todo ello favorece la existencia de un consenso alrededor del mismo, dotando al Convenio de parte de su elevado estatus, y permitiendo que sus resoluciones tengan una fuerza digna de una jurisdicción constitucional. De otro modo la jurisdicción de Estrasburgo conformaría un mero formalismo sin la eficacia práctica (que no teórica) que gozan sus sentencias (recordemos que tienen el carácter de declarativas al igual que muchas otras jurisdicciones internacionales). La trascendencia de la doctrina del margen de apreciación ha conducido a que se encuentre ya en marcha la propuesta de incorporarla como parte expresa del Convenio ${ }^{10}$.

En definitiva, el margen de apreciación juega un papel fundamental a la hora de que el Convenio logre el objetivo de ser una suerte de amparo europeo sin deshacerse, a su vez, de su consideración de tratado internacional (única fórmula jurídica por la que podría existir) ${ }^{11}$. Convirtiendo una aparen-

${ }^{10}$ El protocolo número 15 incorporará una referencia al margen de apreciación en el Preámbulo del Convenio.

11 «En el marco de la dialéctica derechos humanos versus soberanía del Estado, sólo en el supuesto de aplicación de la doctrina del Margen de Apreciación se inclina el Tribu- 
te protección internacional al uso en un verdadero sistema cuasi constitucional de protección de los Derechos Humanos ${ }^{12}$.

El hecho de que su empleo conlleve importantes beneficios no quiere decir que no cuente con ciertos déficits. Uno de ellos será objeto de estudio en la presente investigación, el carácter impreciso de su uso ${ }^{13}$. Otro, al que hasta ahora la doctrina no le ha dedicado mucha atención, es su aplicación no ya por el TEDH, sino por los tribunales de los propios Estados miembros, en un claro ejemplo de por dónde no debería ir el «diálogo» entre las jurisdicciones nacionales y Estrasburgo ${ }^{14}$.

Esta deferencia otorgada por el TEDH a los Estados parte no es absoluta sino que cuenta con ciertas limitaciones que varían en función de una larga lista de factores o «ingredientes» (como han sido denominados por la doctrina), lo que provoca un alto grado de inseguridad jurídica ${ }^{15}$. Por ello, al ser el margen una doctrina de creación jurisprudencial su empleo difiere dependiendo del derecho protegido así como de las ventajas o inconvenientes de su enjuiciamiento en el caso concreto.

En el siguiente epígrafe se analizarán las pautas específicas que objetivan el uso de la doctrina del margen de apreciación en el derecho a elecciones

nal por la defensa de esta soberanía. En el resto de principios jurisprudenciales, la opción es por interpretaciones de la Convención favorables a los derechos humanos», PASTOR Ridruejo, J., Curso de Derecho Internacional Público y Organizaciones Internacionales (16 edición), Tecnos, Madrid, 2012, p. 218.

12 Dicha idea se desprende del estudio de uno de los mayores especialistas nacionales en la materia, el profesor García Roca, «Ahora bien la verdadera justificación racional de la doctrina del margen parece estar tanto en esta equidistancia entre garantía constitucional y protección internacional subsidiaria, como en la tremenda disparidad cultural de las diversas políticas nacionales (...)», GARCÍA RocA, J. (2010), p. 218.

13 En este sentido destacan las aportaciónes de ArAi-TAKAHASHI, Y. (2002), p. 189 y Galetta, D. (1999), p. 750. También en García RocA, J. (2010), pp. 118-119.

${ }^{14}$ Respecto de las vicisitudes de ese «diálogo», ver RodríGUEZ, A., «Hable con él. Las resoluciones del Tribunal Constitucional español previas a las sentencias condenatorias de Tribunal Europeo de Derechos Humanos (Primeras reflexiones sobre las dificultades de un diálogo)», en BALAgUer CALlejón, F. Derecho constitucional y cultura: estudios en homenaje a Peter Häberle, Tecnos, Madrid, 2004, pp. 517-564. Asimismo, en general, sobre la relación entre diálogo e integración RoDRíGUEZ, A., Integración Europea y Derechos Fundamentales, Civitas, Madrid, 2001, pp. 341-342. Ver también NARANJO DE LA CRUZ, R., «Margen de apreciación estatal, libertad religiosa y de crucifijos (o las consecuencias de un deficiente diálogo entre jurisdicciones)», Revista de Derecho Politico, 86, 2013, pp. 81-128.

15 García Roca visualiza ocho ingredientes comunes en la aplicación del margen de apreciación: su aplicación se hace depender de la inexistencia de una base normativa común, de la naturaleza del derecho, de la obligación conforme al Convenio, de la legitimidad del fin, la naturaleza de la regulación, las circunstancias particulares del caso, del equilibrio entre los intereses generales e individuales, así como la imprevisibilidad de las restricciones legales y la ausencia de control. GARCíA ROCA, J. (2010), pp. 131-188. 
libres. Para llegar a ello, los materiales de trabajo lo conformarán las sentencias del Tribunal de Estrasburgo que la han aplicado a este derecho.

\section{ALCANCE DEL MARGEN DE APRECIACIÓN EN LAS SENTENCIAS DEL TRIBUNAL EUROPEO DE DERECHOS HUMANOS RELATIVAS AL DERECHO A ELECCIONES LIBRES}

$\mathrm{Al}$ analizar las Sentencias de Estrasburgo relativas al derecho a elecciones libres destaca un patrón común, el amplio margen de apreciación concedido. A pesar de esta consideración, dicho margen no es ilimitado sino que corresponde al TEDH pronunciarse acerca del cumplimiento de las exigencias exigidas por el art. 3 del Protocolo adicional del CEDH. La labor realizada en el presente estudio es localizar dichos límites en el magma jurisprudencial así como dar un diagnóstico acerca del grado de precisión de su uso ${ }^{16}$.

El reconocimiento del margen varía en función de los factores políticos e históricos propios de cada estado. Se consideran conforme al Convenio multitud de situaciones previstas en las legislaciones electorales estatales siempre que garanticen la libre expresión de la voluntad del pueblo a través de unas elecciones libres, honestas y periódicas ${ }^{17}$.

Los límites exigidos en cada supuesto concreto del derecho a elecciones libres dependen, a su vez, del Estado parte que esté siendo enjuiciado. De tal manera, se encuentran dispersos en la jurisprudencia de Estrasburgo los siguientes: la imposibilidad de que los Estados parte reduzcan la protección del derecho hasta alcanzarlos en su propia sustancia y privarlos de su efectividad, evitando decisiones arbitrarias (previsión legal de la medida), persiguiendo un fin legítimo y usando medios proporcionados; la garantía del respeto a la libre expresión del pueblo en las elecciones legislativas lo que implica asegurar la igualdad de trato de todos los ciudadanos; la prohibición de modificaciones en la organización del sistema electoral una vez expresada la libre y democrática elección del pueblo (salvo motivos imperiosos para el orden democrático) ${ }^{18}$.

16 «Gozan los Estados en esta materia de un amplio margen de apreciación; pero corresponde al Tribunal resolver, en última instancia, sobre el cumplimiento de las exigencias del Protocolo núm. I» STEDH Mathieu-Mohin y Clerfayt (§ 52). También STEDH Gitonas (§ 39) y Podkolzina (§ 26) « (...) los derechos garantizados por el artículo 3 no son absolutos, que hay lugar para las «limitaciones implícitas», y que los Estados Contratantes gozan de un amplio margen de apreciación en cuando a las condiciones de elegibilidad. Sin embargo, dichas condiciones no deben reducir los derechos electorales hasta el punto de afectarlos en su propia sustancia, deben perseguir un objetivo legítimo, y los medios empleados no deben ser desproporcionados».

17 En ese sentido, STEDH Py contra Francia ( $\$ 44$ a $\S 46)$.

18 Para identificar los límites al margen de apreciación, de creación jurisprudencial, ha sido necesario realizar un completo análisis jurisprudencial en la materia. Los casos más relevantes son: 
Caso Mathieu-Mohin y Clerfayt contra Bélgica. Se pone en cuestión si respeta el art. 3 del Protocolo adicional del Convenio el hecho de que en un territorio específico perteneciente a la región de Bruselas (Hal Vilvorde) los diputados o senadores elegidos que juran su cargo en francés no puedan participar en los asuntos de interés de aquella región (imposibilidad de pertenecer al Consejo Flamenco) al sólo poder hacerlos los flamencos (neerlandés). Aún así si forman parte del la Cámara con plenas funciones. Esto se debe a que al «pertenecer» esa región particular a la parte flamenca pero poder elegir a representantes de lengua francesa (valones) ellos podrán elegir si integrarse en el grupo francófono y, por lo tanto, sin competencias en Hal Vilvorde o por el contrario en el grupo flamenco, jurando en ese idioma, y si tener competencias en ese territorio.

Caso Matthews contra Reino Unido. La señora Matthews residente en Gibraltar interpone recurso ante el TEDH debido a la imposibilidad de participar en las elecciones al PE (al considerarse, en virtud de la legislación inglesa, que el Acta de 1976 que regula las elecciones al PE no engloba a Gibraltar).

Caso Labita contra Italia. Benedetto Labita fue encarcelado (desde el 21 de abril de 1992 hasta 12 de noviembre de 1994) debido a la consideración de pertenencia a banda mafiosa, siendo la única prueba para tal detención la declaración de otro arrestado mafioso arrepentido (que a su vez se lo había contado un tercero fallecido y a este a su vez otro tercero fallecido) tras un año y medio (y tras numerosos recursos ante diversas instancias para su puesta en libertad) el Tribunal de Trapani lo asolvió por falta de pruebas (sentencia confirmada por el Tribunal de Apelación de Palermo). Una vez puesto en libertad al sujeto se le aplicaron una serie de medidas preventivas excluyendo al demandante de las listas electorales debido a la pérdida de sus derechos civiles.

Caso Selim Sadak y otros contra Turquía. Tras una Sentencia del Tribunal Constitucional turco (Türkiye Cumhuriyeti Anayasa Mahkemesi) en la que se ilegalizaba a un partido político (DEP) por realizar actuaciones contrarias a la constitución (se consideró que había vulnerado la integridad territorial del estado y la unidad de la nación). Los diputados turcos, pertenecientes a ese partido, son apartados de sus funciones. Asimismo fueron condenados por diversos delitos.

Caso Aziz contra Chipre. Se prohíbe ejercer el derecho al voto alegando que, en virtud del art. 63 de la Constitución de Chipre, los miembros de la comunidad turco-chipriota no podían ser incluidos en el censo electoral greco-chipriota. Lo llamativo es que desde el año 1963 debido al control de la parte turco-chipriota estos se encontraban privados de ejercer su derecho a elegir al 30\% del Parlamento que le corresponde y, por lo tanto, de facto el resto de turco-chipriotas residentes en las zonas greco-chipriotas se encuentran privados del ejercicio del derecho de sufragio.

Caso Melnychenko contra Ucrania. Un refugiado ucraniano en EEUU es declarado en busca y captura por la supuesta comisión de determinados delitos penales. Al año siguiente (2002) el Partido Socialista de Ucrania nombró al demandante candidato para las elecciones al Verkhovna Rada, inscripción que fue denegada argumentándose que éste residía en USA y no en Ucrania (durante los últimos 5 años) como era requisito, además de que este había aportado datos falsos acerca de su lugar y periodo de residencia durante dicho periodo.

Caso Py contra Francia. El señor Bruno Py (profesor universitario de derecho privado y funcionario) fue nombrado como docente en la Universidad francesa del Pacífico situada en Nueva Caledonia (territorio de ultramar francés) empadronándose allí y siéndole concedido el padrón general pero no el electoral especial. Tras unas elecciones de autodeterminación de Nueva Caledonia (en las que no pudo participar al no poder justificar su domicilio constante en la localidad desde diez años antes a dichas elecciones) se firmó un acuerdo por el que Nueva Caledonia adquiría nuevas competencias en su propia gestión. 
Por otro lado, a diferencia de los artículos 8 a 11 del Convenio ${ }^{19}$ en los que sus respectivos apartados segundos fijan la posibilidad de restringir los derechos reconocidos siempre que los Estados parte cumplan con lo establecido en los mismos, el art. 3 del Protocolo adicional del Convenio ${ }^{20}$ no establece expresamente la posibilidad de limitar el derecho a las elecciones libres. Esta ausencia de regulación ha propiciado que los límites de su restricción sean fruto de las construcciones jurisprudenciales del Tribunal. A pesar de ello, puede considerarse que las restricciones amparadas directamente en el Convenio quedan excluidas del ámbito de aplicación del margen. Del modo en que se ha hecho referencia en apartados anteriores, este es considerado como una deferencia de Estrasburgo a los Estados parte con la finalidad de conciliar el carácter subsidiario a la vez que integrador del Convenio, por lo que a pesar de contradecir el Convenio, Estrasburgo declara la actuación del Esta-

Se estableció (a raíz de dicha atribución de competencias) un periodo de residencia de diez años para poder participar en las elecciones de los miembros del Congreso (de Nueva Caledonia) y de las asambleas provinciales. Con la presente regulación en vigor el demandante solicitó la inscripción en el padrón electoral especial para poder participar en las elecciones al Congreso y de las asambleas provinciales del municipio de Nouméa de 9 de mayo de 1999, siendo esta rechazada al no poder justificarse un domicilio constante en Nueva Caledonia desde hacía 10 años.

Caso Hirst contra Reino Unido. Privación del derecho al sufragio activo de un condenado a cadena perpetua discrecional debido a la peligrosidad del sujeto a pesar de haber cumplido su condena.

Caso Kavakçi contra Turquía. La señora Merve Safa Kavakçi fue elegida diputada en la Gran Asamblea de Turquía por el partido Fazilet. A pesar de ello; se le impidió jurar su cargo y fue expulsada del hemiciclo por el hecho de portar un velo islámico. Además, se le privó de la nacionalidad turca (al conocerse que había obtenido también la americana) y se le inhabilitó de su cargo de parlamentaria al disolverse el partido Fazilet por ir en contra de las normas de laicidad.

Caso Kovach contra Ucrania. El señor Kovach se presentó como candidato en las elecciones parlamentarias ucranianas (parlamento unicameral denominado Verkhovna) obteniendo más votos que su oponente. Aun así, no fue elegido debido a la invalidación de los resultados de ciertos distritos. Se consideró que habían concurrido ciertas irregularidades, sobre todo, la inclusión en urnas de papeletas ilegales.

Caso Etxeberria, Barrena Arza, Nafarroako Autodeterminazio Bilgunea y Aiarako y otros contra España. Anulación de las candidaturas de los demandantes tras un recurso electoral presentado por el Abogado del Estado y el Ministerio Fiscal debido a que el Tribunal Supremo consideró que la finalidad de las mismas era continuar con la actividad de tres partidos ilegalizados y disueltos.

19 Relativos al derecho al respeto a la vida privada y familiar; a la libertad de pensamiento, de conciencia y de religión; a la libertad de expresión; y a la libertad de reunión y asociación.

${ }^{20}$ Recordemos su tenor literal. «Las Altas Partes Contratantes se comprometen a organizar, a intervalos razonables, elecciones libres con escrutinio secreto, en condiciones que garanticen la libre expresión de la opinión del pueblo en la elección del cuerpo legislativo». 
do en cuestión conforme al mismo siempre que quede comprendida dentro de un marco que establece su propia jurisprudencia. Por ello, en el momento que el propio Convenio fija la posibilidad de restringir un derecho, los Estados parte están capacitados para aplicar esa restricción sólo por el hecho de que aparezca regulada en el Convenio, esto es, sin necesidad de acudir al margen de apreciación.

En función de todo lo anterior, podemos establecer hasta seis pautas jurisprudenciales diferenciadas en relación con los límites del margen de apreciación en el derecho a elecciones libres. Estos son los siguientes:

En primer lugar, la imposibilidad de que los Estados parte reduzcan la protección del derecho hasta alcanzarlos en su propia sustancia y privarlo de su efectividad. Si fuese de otro modo, cualquier acto contrario al derecho a elecciones libres quedaría amparado por el margen de apreciación. El presente límite aparece citado en prácticamente todas las sentencias de Estrasburgo sobre el particular, siendo, por lo tanto, uno de los criterios más relevantes a la hora de realizar el correspondiente juicio. Numerosos casos hacen referencia a este límite haciendo uso de términos parecidos tales como «ha de asegurarse de que los requisitos establecidos no disminuyen los derechos de que se trata hasta afectarles en su propia esencia y hacerlos ineficaces» $»^{21}$, «no se puede alegar que las restricciones enjuiciadas vulneraran la sustancia misma de los derechos garantizados» $»^{22}$, se ha «atentado contra la esencia misma del derecho de voto tal y como lo garantiza a la demandante el artículo 3 del Protocolo adicional $»^{23}$. Asimismo, entre otros, en el Caso Aziz el Tribunal consideró que la actuación de Chipre no estaba amparada por el margen de apreciación al negársele al demandante la esencia misma del derecho al voto ${ }^{24}$.

En segundo lugar, para que la medida quede amparada por el margen de apreciación nacional deberá estar prevista legalmente, evitándose así decisiones arbitrarias. Así lo ha ido exigiendo la jurisprudencia del TEDH: «El procedimiento de elegibilidad debe contener suficientes salvaguardas como para evitar decisiones arbitrarias» ${ }^{25}$, «En opinión del Tribunal, los demandantes podían razonablemente esperar que esta disposición fuera aplicada en su caso. En efecto, fue publicada en el Boletín Oficial y estaba en vigor en el momento en que las candidaturas de las agrupaciones electorales en litigio fueron anuladas, lo que confería a la Ley un carácter suficientemente previsible y accesible $~^{26}$, «El Tribunal reitera que una norma es «predecible» siem-

${ }^{21}$ STEDH Mathieu-Mohin y Clerfayt contra Bélgica (§ 52).

${ }_{22}$ STEDH Ahmed y otros contra Reino Unido (\$ 75).

${ }^{23}$ STEDH Matthews contra Reino Unido (\$ 65).

${ }^{24}$ STEDH Aziz contra Chipre (\$30).

25 STEDH Caso Melnychenko contra Ucrania (\$59).

${ }^{26}$ STEDHo Etxeberria, Barrena Arza, Nafarroako Autodeterminazio Bilgunea y Aiarako y otros contra España (§ 51). 
pre y cuando esté formulada con la suficiente precisión como para permitir a cualquier individuo - con la asesoría adecuada si lo necesitase- regular su conducta ${ }^{27}$. Por último, en el Caso Kovach, el Tribunal afirma que la actuación del Estado quedará circunscrita al margen de apreciación siempre que los criterios de privación estén formulados, esto es, circunscrita con suficiente precisión por la legislación interna ${ }^{28}$.

En tercer lugar, la restricción debe buscar un fin legítimo. En el caso $P y$, se exige un periodo de residencia para poder participar en las elecciones de Nueva Caledonia (dependencia francesa), restricción que, en palabras del TEDH, queda amparada dentro del margen al buscar una vinculación entre territorio y cuerpo electoral para participar en las elecciones al Congreso tras adquirir competencias para su propia gestión ${ }^{29}$.

En cuarto lugar, que los medios utilizados no sean desproporcionados. «Ha de asegurarse (...) que los medios empleados guardan, a este respecto, la debida proporción $»^{30}$. Uno de los ejemplos más ilustrativo lo protagoniza el Caso Labita, en el que se privó del ejercicio del sufragio activo y pasivo a un ciudadano italiano una vez que había sido absuelto de los delitos que se le acusaba. Dicho impedimento aparecía regulado ante cualquier persona sospechosas de pertenecer a la mafia. Estrasburgo falla argumentando que a pesar de buscar un fin legítimo, evitar la influencia de grupos mafiosos en los diferentes colegios electorales, la presente restricción no es proporcionada al producirse una vez que había sido decretada su absolución ${ }^{31}$. También el Caso Selim Sadak el Tribunal consideró que no era proporcional la privación de la condición de diputados debido a la ilegalización de su partido por declaraciones del ex presidente del mismo. A pesar de que el fin era legitimo (mantenimiento de la seguridad pública y de la seguridad nacional así como la protección del orden democrático y la integridad territorial) la medida se considera extremadamente severa y, por lo tanto, no proporcional, siendo contraria a la sustancia del precepto ${ }^{32}$. Por último se encuentra el Caso Hirst en el que se declaró que era contraria al Convenio la restricción del derecho al sufragio de forma automática a todos los reclusos condenados que cumplan su pena independientemente de la naturaleza o gravedad del delito que hayan cometido y de su situación personal ${ }^{33}$.

27 STEDH Seyidzade contra Azerbaijan ( $\$ 33)$.

${ }^{28}$ STEDH Kovach contra Ucrania (\$54).

29 «El Tribunal considera que la condición de residencia persigue, en este caso, un fin legítimo», STEDH Py contra Francia $(\$ 52)$.

${ }_{30}$ STEDH Mathieu -Mohin y Clerfayt contra Bélgica (\$52).

31 STEDH Labita contra Italia (\$201).

${ }^{32}$ STEDH Selim Sadak y otros contra Turquía (§35- §40).

33 «Esta disposición impone una restricción global a todos los reclusos condenados que cumplen su pena y se les aplica automáticamente cualquiera que sea la duración de su pena e independientemente de la naturaleza o gravedad del delito que hayan cometido y 
En quinto lugar, las restricciones no podrán trabar la libre expresión del pueblo en las elecciones legislativas ${ }^{34}$. La esencia de este límite aparece recogida en el Caso Kavakçi, «ninguna de las condiciones establecidas deben trabar la libre expresión del pueblo sobre la elección del cuerpo legislativo -dicho de otra manera-, deben reflejar, o no oponerse, la preocupación de mantener la integridad y la efectividad de un proceso electoral que trate de determinar la voluntad del pueblo a través del sufragio universal $»^{35}$. Dentro de este quinto límite al margen se encuentra a su vez otro, el aseguramiento de la igualdad de trato de todos los ciudadanos ${ }^{36}$. En el Caso Kovach se fundamenta a la perfección: «(...) los Estados Contratantes gozan de un amplio margen de apreciación, siempre que ellos aseguren la igualdad en el trato para todos los ciudadanos. Es lógico que todos los votos tengan que tener necesariamente el mismo peso en relación al resultado de las elecciones o que todos los candidatos deban tener las mismas posibilidades de victoria $)^{37}$.

En sexto y último lugar, el margen de apreciación no podrá amparar modificaciones a posteriori en la organización del sistema electoral. El Tribunal considera una vez que se ha ejercitado el derecho ninguna modificación podrá alterar la voluntad del electorado, con la única excepción de que se produzcan motivos imperiosos para el orden democrático ${ }^{38}$.

de su situación personal. Es necesario considerar que dicha restricción general, automática e indiferenciada a un derecho consagrado por el Convenio y de una importancia crucial, sobrepasa el margen de apreciación aceptable, por muy amplio que sea, y es incompatible con el artículo 3 del Protocolo núm. 1.» STEDH Hirst contra Reino Unido (\$82).

34 «(..) estos requisitos no deben contrariar «la libre expresión de la opinión del pueblo en la elección del Cuerpo Legislativo»»), STEDH Mathieu-Mohin y Clerfayt contra Bélgica (\$52).

35 STEDH Kavakçi contra Turquía (§41). Asimismo, en la STEDH Paschalidis, Koutmeridis y Zaharakis contra Grecia $(\$ 28)$.

36 «Los sistemas electorales pretenden responder a objetivos que, a veces, son difíciles de armonizar: de una parte, reflejar con fidelidad las opiniones del pueblo; de otra canalizar las corrientes ideológicas para promover la formación de una voluntad política de suficiente claridad y coherencia. Por ello, la frase «en condiciones que garanticen la libre expresión de la opinión del pueblo en la elección del Cuerpo (o Poder) Legislativo» implica esencialmente, además de la libertad de expresión, ya protegida por el artículo 10 del Convenio, el principio de la igualdad de trato de todos los ciudadanos en el ejercicio de su derecho de voto y de presentarse a las elecciones», STEDH Mathieu-Mohin y Clerfayt contra Bélgica $(\S 54)$.

37 STEDH Kovach contra Ucrania $(\$ 49)$.

38 «Asimismo, una vez expresada la elección del pueblo, libre y democráticamente, ninguna modificación posterior en la organización del sistema electoral puede cuestionar esta elección, salvo en presencia de unos motivos imperiosos para el orden democrático», STEDH Paschalidis, Koutmeridis y Zaharakis contra Grecia (§ 28). De igual forma, STEDH Kavakçi contra Turquía (§ 41). 
En definitiva, la jurisprudencia de Estrasburgo desarrolla un marco dentro del que una actuación de un Estado parte a pesar de restringir el derecho a elecciones libres no vulnera el Convenio. Además, la labor jurisprudencial combina unos límites generales (la imposibilidad de alcanzar el derecho en su propia esencia y privarlo de efectividad, evitando decisiones arbitrarias, en base a una finalidad legítima y haciendo uso de unos medios proporcionados) con otros específicos del presente derecho (el respeto de la libre expresión del pueblo en las elecciones legislativa y la imposibilidad de que una modificación posterior pueda cuestionar la elección).

\section{CONCLUSIONES}

El presente estudio ha tratado de aproximarse a uno de los déficits más citados por la doctrina especializada en la doctrina del margen de apreciación nacional desarrollada por el TEDH: la imprecisión de su uso. Dicha imprecisión es, en cierto modo, consustancial a las ciencias jurídicas. Ya se sabe que es difícil encontrar dos casos iguales, siendo los tribunales los encargados de aplicar la ley al caso concreto. Quizás sin imprecisión no pueda existir una verdadera justicia. Si fuese así, sentencias de los tribunales pasarían por las manos de los jueces sin tener en cuenta una serie de factores específicos que hacen que ese concreto supuesto sea único.

Si la aplicación de un derecho depende del caso concreto en una jurisdicción nacional, al entrar en juego 47 países diferentes con realidades sociales tan diversas esta sujeción se eleva exponencialmente. En este sentido, el TEDH realiza una labor imprescindible en la protección de ciertos derechos inherentes a toda sociedad democrática. Para ello es imprescindible elaborar, como efectivamente ocurre, un estudio completo de la legislación estatal vigente así como de los diversos factores históricos, culturales, sociales, etc. que le atañen. Esta labor es todavía más importante si cabe a la hora de declarar que una actuación estatal, a pesar de que a priori pudiera parecer que vulnera el Convenio, entra dentro del margen de apreciación nacional.

Considero que esa cierta imprecisión dota al margen de una versatilidad sin tener por qué producir una inseguridad jurídica. Si fuera de otro modo el margen de apreciación perdería su esencia. Recordemos que es una creación jurisprudencial y cuya finalidad es conciliar la homogeneidad exigida en el Convenio en torno a los derechos allí reconocidos y la subsidiariedad propia de un tratado internacional. Es más, probablemente sin él este sistema de protección de Derechos Humanos no gozaría de su buena salud.

El análisis realizado en este estudio nos ha permitido estudiar en la jurisprudencia de Estrasburgo el funcionamiento del margen de apreciación en el derecho a elecciones libres y encontrar una serie de límites claro a su aplicación.

Que existan una serie de límites en la aplicación de la doctrina del margen de apreciación no quiere decir que su uso quede complemente restringido, 
sino que implica que este debe ser aplicado en consciencia en el momento en que la situación lo requiera. Lo que pretende la propia jurisprudencia europea es establecer un mínimo exigible en la aplicación del margen de apreciación en el Derecho a elecciones libres.

En definitiva no deberiamos llamar imprecisión a su uso. El margen fue creado para lidiar con la diversidad de los Estados sometidos a la jurisdicción del TEDH. Por ello, no se debe olvidar que lo que pretende esta figura es conciliar la diversidad estatal con el cumplimiento efectivo de unos derechos especialmente sensibles.

\section{BIBLIOGRAFÍA CITADA}

ARAI-TAKAHASHI, Y., The margin of appreciation doctrine and the principle of proportionality in the jurisprudence of the ECHR, Intersentia, Antwerp-OxfordNueva York, 2002.

De GoutTeS, R., «La théorie de la marge d'appreciation dans la jurisprudence récente de la Cour Européenne des Droits de l'Homme», Revue Trimestrielle des Droits de l'Homme, $\mathrm{n}^{\mathrm{O}}$ 24, 1995, pp. 566-614.

GaletTA, D., «Il principio de proporzionalità nella Convenzione Europea dei Diritti dell'Uomo, fra principio di necessarietà e doctrina del margine di apprezzamento statale: riflessioni generali su contenuti e rilevanza effettiva del principio», Rivista Italiana di Diritto Pubblico Comunitario, no 3-4, 1999, pp. 743-771.

GARCÍA ROCA, J., El margen de apreciación nacional en la interpretación del Convenio Europeo de Derechos Humanos: soberanía e integración, Civitas, Madrid, 2010.

- y Santolaya, P., (eds.) La Europa de los Derechos: el Convenio Europeo de Derechos Humanos, Centro de Estudios Políticos y Constitucionales, Madrid, 2009.

GREER, S., The margin of appreciation: interpretation and discretion under the European Convention on Human Rights, Council of Europe Publishing, Strasbourg, 2000.

NARANJo DE LA CRUZ, R., «Margen de apreciación estatal, libertad religiosa y de crucifijos (o las consecuencias de un deficiente diálogo entre jurisdicciones)», Revista de Derecho Político, 86, 2013, pp. 81-128.

Pastor Ridruejo, J., Curso de Derecho Internacional Público y Organizaciones Internacionales (16 edición), Tecnos, Madrid, 2012.

RODRÍGUEZ, A., Integración europea y derechos fundamentales, Civitas, Madrid, 2001. - «Hable con él. Las resoluciones del Tribunal Constitucional español previas a las sentencias condenatorias de Tribunal Europeo de Derechos Humanos (Primeras reflexiones sobre las dificultades de un diálogo)», en BALAGUER CALLEJón, F. Derecho constitucional y cultura: estudios en homenaje a Peter Häberle, Tecnos, Madrid, 2004, pp. 517-564.

Yourow, H., The margin of appreciation doctrine in the dynamics of European Human Rights jurisprudence, Kluwe Law International, La Haya/Boston/Londres, 1996.

«The Margin of Appreciation Doctrine in the dynamics of European Human Rights Jurisprudence», Connecticut Journal of Int'l Law, Vol. 3:111, 1987, pp. 111-159. 


\section{REFERENCIAS JURISPRUDENCIALES CITADAS}

STEDH Mathieu-Mohin y Clerfayt contra Bélgica de 2 marzo 1987.

STEDH Matthews contra Reino Unido de 18 febrero 1999.

STEDH Labita contra Italia de 6 abril 2000.

STEDH Selim Sadak y otros contra Turquía de 11 junio 2002

STEDH Aziz contra Chipre de 22 junio 2004.

STEDH Melnychenko contra Ucrania de 19 octubre 2004

STEDH Py contra Francia de 11 enero 2005.

STEDH Hirst contra Reino Unido de 6 octubre 2005

STEDH Kavakçi contra Turquía de 5 abril 2007.

STEDH Kovach contra Ucrania de 7 febrero 2008.

STEDH Paschalidis, Koutmeridis y Zaharakis contra Grecia de 10 abril 2008

STEDH Etxeberria, Barrena Arza, Nafarroako Autodeterminazio Bilgunea y Aiarako y otros contra España de 30 junio 2009.

TITLE: The National margin of appreciation in the decisions of the ECtHR concerning the right to free elections.

RESUMEN: A pesar de que el margen de apreciación nacional se ha caracterizado como una figura vaga e imprecisa, si se indaga en la jurisprudencia del Tribunal Europeo de Derechos Humanos se pueden extraer una serie de criterios que objetivan su aplicación en el derecho a elecciones libres establecido en el Artículo 3 del Protocolo adicional del Convenio Europeo de Derechos Humanos. En el presente estudio se han tratado de localizar las diferentes pautas que el Tribunal de Estrasburgo tiene en cuenta para decidir si determinadas restricciones del derecho a elecciones libres de un Estado parte quedan amparadas bajo el paraguas del margen de apreciación.

PALABRAS CLAVE: Derecho a elecciones libres, margen de apreciación, TEDH, déficit, imprecisión.

ABSTRACT: Although the Margin of appreciation is characterized as a shadowy figure, if we investigate in the European Court of Human Rights jurisprudence we can draw a number of criteria that aim its application in the right to free elections as established in Article 3 of the additional Protocol to the European Convention on Human Rights. Thus, in this research we have tried to locate the different patterns that the Strasbourg Court takes into account in deciding whether certain restrictions on the right to free elections of a State party are covered under the umbrella of the margin of appreciation.

KEYWORDS: Right to free elections, margin of appreciation, ECtHR, deficit, lack of precision. 